\title{
Design of books inventory with RFID antenna in library management system
}

\author{
Ching-Chien Cheng ${ }^{1, *}$, Sung-Tsun Shih ${ }^{2}$, Kong-Xin Cheng $^{1}$, Huang-Kuang Kung ${ }^{1}$, and Chin-Yu Wang ${ }^{1}$ \\ ${ }^{1}$ Institute of Mechatronics Engineering, Cheng Shiu University, Kaohsiung City, Taiwan \\ ${ }^{2}$ Department of Electronic Engineering, Cheng Shiu University, Kaohsiung City, Taiwan
}

\begin{abstract}
A $915 \mathrm{MHz}$ printed radio-frequency-identification (RFID) antennas with the characteristics of good gain and omnidirectional beam wave is constructed and evaluated in this study. The objective is to find out their best reading rates for providing effective wireless communications among RFID antenna during the library book inventory process. And an optimal library inventory system which is based on electromagnetic identification (EMID) technology is proposed, which is constructed to find the optimal tag location for a book, test the tag readability for bookshelves, and connect a couple of multi-layer bookshelves with multiplexers and updat the tag reading status in the database of the computer terminal. The fabricated antenna reader and the proposed system are embedded into different locations of bookshelves and tested at the library of Cheng Shiu University in Taiwan. According to the experimental results, the designed prototype of the antenna reader has the characteristics of the directional radiation pattern, good gain, simple shape, low cost and is easy to be integrated into the bookshelf. And the designed library inventory system can authenticate the location of a book automatically. They can benefit administrating librarians with the capabilities of decreasing the library inventory processing time and reducing the possibility of the books being misplaced.
\end{abstract}

\section{Introduction}

In the past, barcode labels and electromagnetic (EM) strips are two common technologies used to support the identification and anti-theft capabilities in the library inventory system. However, the barcode labels could be only stuck on the book once, manually scanned, easily damaged and the EM strips don't support resource identification capability [1]. In recent years, in order to overcome the weaknesses mentioned above, RFID wireless communication technology has replaced the barcode label and magnetic strip with the identification and anti-theft detection capabilities in the library inventory management. Compared with using barcodes in the library inventory management, a RFID tag could be read more than ten-thousand times and could support more convenient and efficient advantages on check-out and return processes [2-6].

Several literatures have been proposed for the smart shelf application in library, including utilizing mobile robot to improve inventory management [7], applying micro-strip lines to improving tag detecting capability [8]. However, these methods are not good for the needs of real time and low cost. As for the use of RFID technology in the bookshelf applications, Kim and Choi [9] proposed a wideband rectangular loop tag antenna for ultra-high frequency RFID library management systems. Another paper proposed a small wideband circularly polarized patch antenna printed on the low-cost FR-4 material for RFID smart bookshelves in libraries [10]. The proposed antenna was operated at a center frequency of $915 \mathrm{MHz}$ and the wave-beam width is $115^{\circ}$.

Reviewing some references applying UHF RFID Antenna in the library inventory managements, Kim et al. [11] designed a loop antenna for UHF band RFID tag used for a library management system. To achieve the wide-band characteristic, both vertical sides of a loop antenna are widened. Lukas et al. [12] and Kaiwen et al. [13] proposed UHF omnidirectional RFID antenna researches to increase the wireless identification and tracking capabilities for the item-level RFID application. Both literatures presented the designs of UHF RFID tag antennas which supported omnidirectional reading patterns and provided great potential for item-level RFID applications in libraries for tracking the books.

Golding and Tennant [14] investigated the factors that may affect the reading rate of an inventory reader in a library. The investigated factors were reading distance, tag location, number of sweeps and sweep direction. Wang [15] studied the RFID-based methodology and approaches that support library services and management, including sensor gate control, circulation, inventory, searches and utilization statistics. The study also discussed barriers, challenges and future work about RFID applications in libraries and concluded that RFIDbased technology would improve digital archives and

Corresponding author: chching@kmvs.km.edu.tw 
digital humanities in library systems. Zhang and Shi [16] and Bin Abdullah, etc. [17] proposed two literatures related to self services of library management systems. Zhang and Shi strongly pointed out the necessity of the new RFID technology of self-service book borrowing and returning system in library, which would replace the barcode technology and accelerate the library's selfservice process. Bin Abdullah, etc. developed an integrated RFID system with graphical user interface (GUI) at the host PC. The study aims to develop an automatic library shelf-management system to assist the librarians for more efficient shelf-management to find any misplaced books on the shelf.

In addition, when reviewing some other RFID related literatures [18-23], two comments were made: (1) such an intelligent plan may not meet the library demand because library internal disturbances, which could affect the RFID operation, such as metal conditions, electric motion-communication wave, and electric wireless network wave should be taken into consideration; (2) the proposed inventory system should be convenient to all readers. As mentioned above, driven by the advanced ubiquitous computing technology, the authors propose a library inventory system with printed RFID antenna in which the characteristics of good gain and omnidirectional beam wave are constructed and evaluated. The objective is to find out their best reading rates for providing effective wireless communications among RFID antenna during the inventory process. What follows is the application of the RFID antenna design as shown in section 2 , and section 3 which describe the proposed library inventory system based on EMID technology. Then the experimental results are shown in section 4. Finally, the conclusions and discussions are summarized in section 5 .

\section{RFID antenna design (omnidirectional beam antenna)}

Efficacy of reading antenna identification is one of the key factors in the accuracy of the overall RFID inventory management system. So the antenna design is the most important part in whether library inventory management system can read correctly or not. So in this section our proposed RFID antenna design and feature evaluations will be introduced.

In the library inventory system, because the distance among bookshelves is very close and the individual bookshelf has a wider surface with multi-layer factors, the antenna should be designed with the characteristics of a relatively wide beam to cover the detction on all books of the same bookshelves, and should has a smaller radiation power to avoid the detection of shelf books nearby. In order to achieve good detection accuracy, we designed a flatbed printed RFID reader antenna used in the library books inventory. This antenna has a wide beamwidth with omnidirectional radiation characteristics and has good gain features. With reference to the designed patch mentioned in the literature, we first design patch antenna with the center frequency at
915MHz, and then do the size fine-tuning to obtain the RFID antenna mentioned above.

\subsection{RFID antenna design procedure}

The geometry plane and the prototype of the antennas are shown in Fig. 1. Two antennas consist of an upside down patch and rectangle ground substrates. Fig. 1. (a) shows the traditional patch antenna, and Fig. 1. (b) shows our proposed RFID antenna. Here we use dielectric constant 4.4 and FR4 substrate with substrate thickness $h=1.6$ for designing, and the steps of these two antennas are as follows.

Step 1: Calculation of Width (W) of top Patch[13] The width of the MSTPA is given by

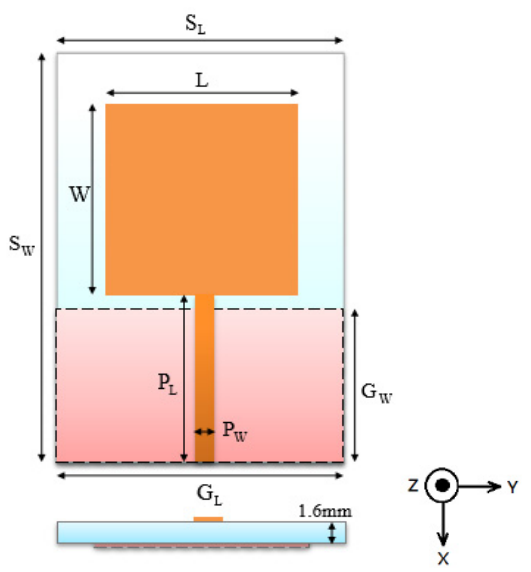

(a) tranditional patch antenna

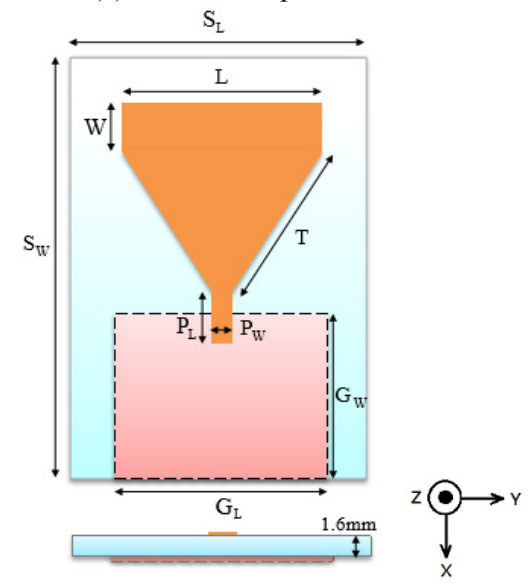

(b) proposed RFID antenna

Fig. 1. Structure of proposed RFID antenna filter (a) tranditional patch antenna (b) proposed RFID antenna.

$W=\frac{c}{2 f_{r}} \sqrt{\frac{2}{\varepsilon_{r}+1}}$

By substituting $\mathrm{C}=3 \times 108 \mathrm{~m} / \mathrm{s}, \quad \varepsilon \mathrm{r}=4.4$ and $\mathrm{fr}=915$

$\mathrm{MHz}, \mathrm{W}=100 \mathrm{~mm}$ can be easily determined.

Step 2: Define the effective dielectric constant ( $\varepsilon$ reff) [24] The equation below illustrates the effective dielectric constant, 
$\varepsilon_{\text {reff }}=\frac{\varepsilon_{r}+1}{2}+\frac{\varepsilon_{r}-1}{2} \sqrt{1+2 \frac{h}{W}}$

By substituting $\varepsilon \mathrm{r}=2.2, \mathrm{~W}=100 \mathrm{~mm}$ and $\mathrm{h}=1.6 \mathrm{~mm}$, $\varepsilon$ reff $=4.556$ can be determined.

Step 3: Define the effective length (Leff) and the effective length is illustrated as [24] :

$$
L_{\text {eff }}=\frac{c}{2 f_{r} \sqrt{\varepsilon_{r e f f}}}
$$

By substituting $\varepsilon$ reff $=4.556, \mathrm{c}=3 \times 108 \mathrm{~m} / \mathrm{s}$ and $\mathrm{fr}=$ $915 \mathrm{MHz}$, Leff $=76.8 \mathrm{~mm}$ can be determined.

Step 4: The length extension is determined. $(\Delta L)$ The length of extension can be illustrated as [24]:

$$
\Delta L=0.412 h \frac{\left(\varepsilon_{\text {reff }}+0.3\right)\left(\frac{W}{h}+0.264\right)}{\left(\varepsilon_{\text {reff }}-0.258\right)\left(\frac{W}{h}+0.8\right)}
$$

By substituting $\varepsilon$ reff $=4.446$ and other corresponding values, $\Delta \mathrm{L}=0.7385 \mathrm{~mm}$ can be determined.

Step 5: Actual length of top patch (L): is determined. The actual length of top patch is obtained as [24]:

$L=L_{\text {eff }}-2 \Delta L$

By substituting Leff $=76.8 \mathrm{~mm}$ and length extension $\Delta \mathrm{L}$ $=0.7385 \mathrm{~mm}$, the actual length can defined as $\mathrm{L}=76$ $\mathrm{mm}$.

Step 6 : Following the top patch chamfering and size fine-tuning, circuit style by RFID antenna is shown in Fig. 1 (b).

\subsection{RFID antenna fabricated}

With the above design of the antenna step, the center frequency of the antenna can be estimated, and the traditional patch antenna parameters based on the dielectric constant 4.4 and the FR4 substrate with substrate thickness $\mathrm{h}=1.6$ can be calculated. Similarly, the RFID omni-directional radiation antenna size can be obtained after fine-tuning and chamfering. Table 1 shows the parameter table of the calculated tranditional patch antenna size and the fine-tuned Proposed RFID antenna size.

By starting from the top view of Fig. 1 (b), the lengths of each side of upside down triangle patch are $\mathrm{L}=$ $41 \mathrm{~mm}, \mathrm{~W}=14 \mathrm{~mm}, \mathrm{G}_{\mathrm{L}}=55 \mathrm{~mm}, \mathrm{G}_{\mathrm{W}}=64.5 \mathrm{~mm}, \mathrm{P}_{\mathrm{L}}=3 \mathrm{~mm}$, $\mathrm{P}_{\mathrm{W}}=14.5 \mathrm{~mm}$ and $\mathrm{T}=60 \mathrm{~mm}$, respectively, with a twolayer FR4 board there. The photograph of the proposed omnidirectional beam RFID antenna is shown in Fig. 2. The antenna consists of an upside down triangle patch and rectangle ground substrates. The antenna is printed on a $65 \mathrm{~mm} \times 150 \mathrm{~mm}$ dielectric substrate. The detecting point is located at the center area of the upside down triangle printed patch.
Table 1. Comparison of patch parameter for antennas.

\begin{tabular}{|c|c|c|}
\hline Parameter & $\begin{array}{l}\text { Tranditional Patch } \\
\text { Antenna }\end{array}$ & $\begin{array}{l}\text { Proposed RFID } \\
\text { Antenna }\end{array}$ \\
\hline $\mathbf{L}$ & 76 & 41 \\
\hline $\mathbf{W}$ & 100 & 14 \\
\hline $\mathbf{S}_{\mathbf{L}}$ & 150 & 65 \\
\hline $\mathbf{S}_{\mathbf{W}}$ & 220 & 150 \\
\hline $\mathbf{G}_{\mathbf{L}}$ & 150 & 55 \\
\hline $\mathbf{G}_{\mathbf{W}}$ & 75 & 64.5 \\
\hline $\mathbf{P}_{\mathbf{L}}$ & 4 & 3 \\
\hline $\mathbf{P}_{\mathbf{W}}$ & 80 & 14.5 \\
\hline $\mathbf{T}$ & & 60 \\
\hline
\end{tabular}

(unit: $\mathrm{mm}$ )
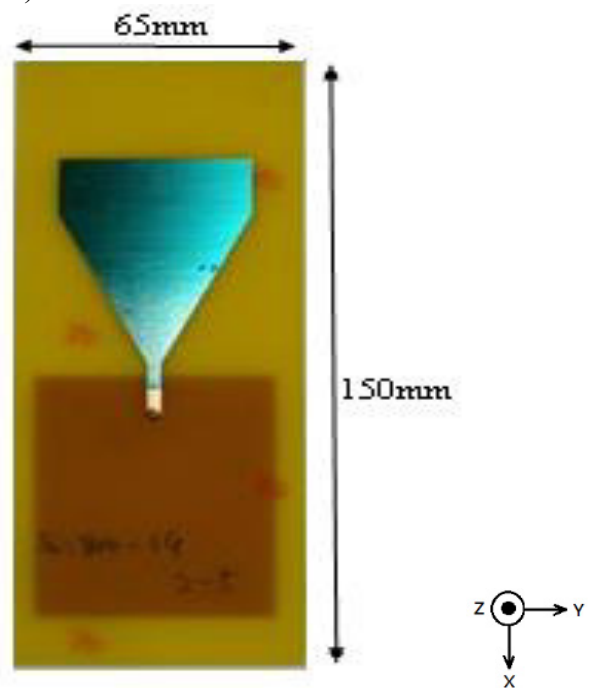

Fig. 2. photograph of the proposed RFID antenna.

\subsection{RFID antenna measurement results}

RFID antenna readers have been fabricated on the printed circuit board (PCB) with the operating frequency at $915 \mathrm{MHz}$. In this paper, three performances, including the radiation, return losses, and peak gain, are tested by using vector network analysis device named Agilent PNA N5230A and simulated by using antenna design kit named ANSOFT HFSS. Fig. 3 shows the types of proposed antenna radiation patterns which are displayed in $\mathrm{YZ}$ and $\mathrm{XZ}$ planes with the operating frequency at 915 MHz. The wavebeam width of antenna is omnidirectional and the wave-beam for the power is greater than $0 \mathrm{~dB}$ is 360 degree. Fig. 4 shows the measured $-10 \mathrm{~dB}$ return losses from $795 \mathrm{MHz}$ up to 1 GHz. This indicates that three antenna are all suitable for the ultra high frequency (UHF) RFID application. Fig. 5 shows the measured peak gain of antenna. For our proposed antenna, the peak gain for the proposed antennas is $3.01 \mathrm{~dB}$ at $915 \mathrm{MHz}$ operating frequency. Fig. 6 and Fig. 7 are the radiation patterns of RFID antenna from $+\mathrm{X}$ and $+\mathrm{Y}$ 


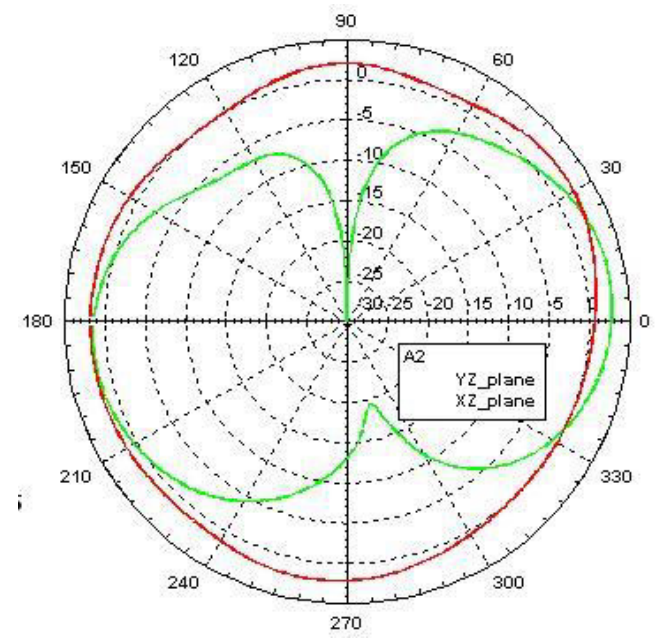

Fig. 3. Measured radiation patterns for $\mathrm{XZ}$ and $\mathrm{YZ}$ plane at $915 \mathrm{MHz}$.

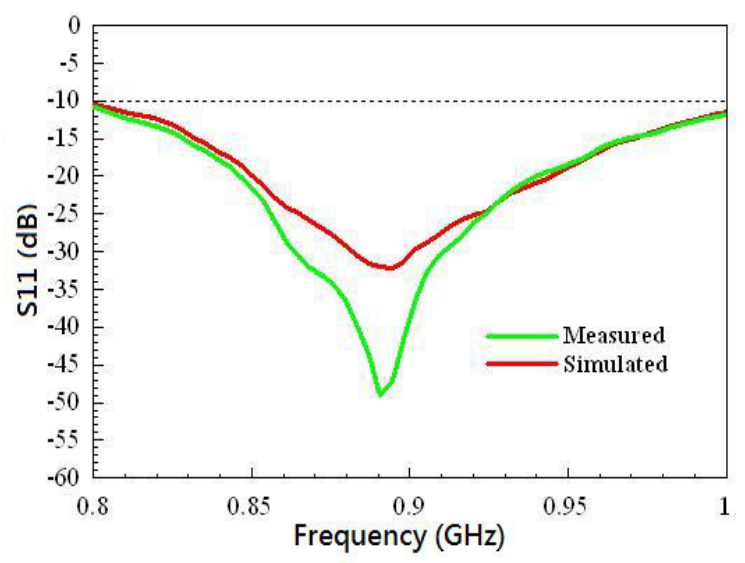

Fig. 4. Measured return losse of RFID antenna.

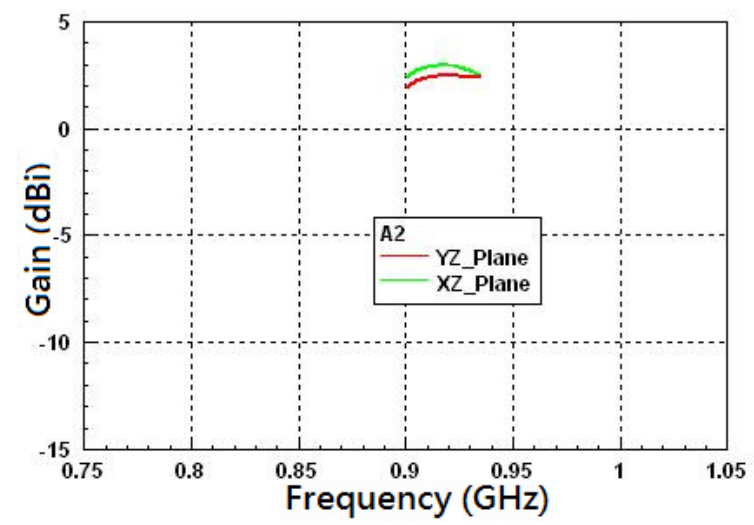

Fig. 5. Measured total field of RFID maximum gain.

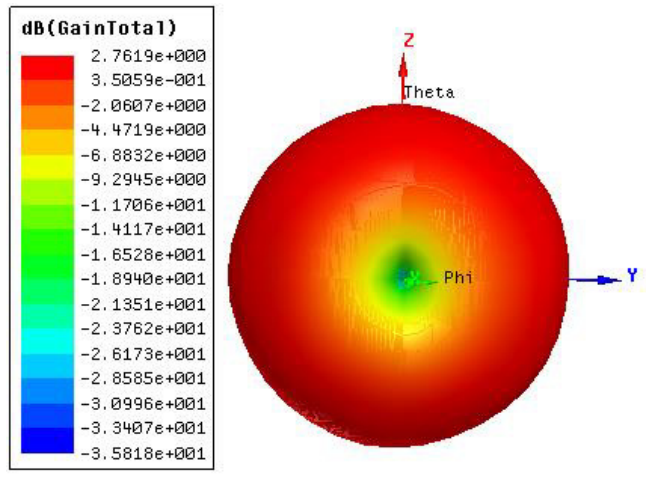

Fig. 6. Radiation pattern of RFID antenna (from $+X)$.

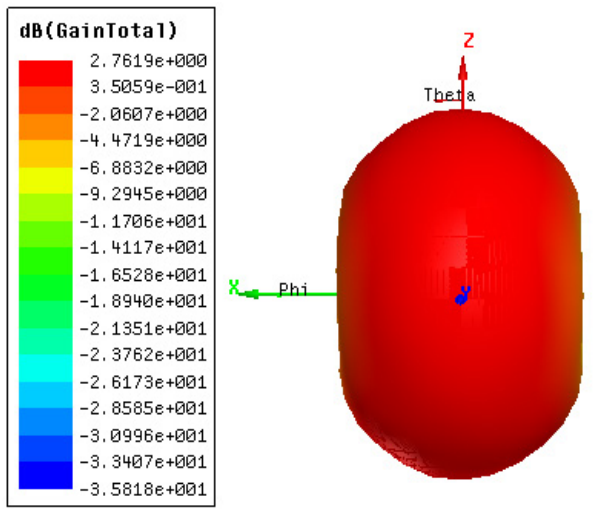

Fig. 7. Radiation pattern of antenna (from $+Y$ ).

\section{Library inventory system design}

Fig. 8 illustrates the flow chart of the optimal library inventory technology with four steps: deciding the tag type, finding the optimal tag location for a book, testing the tag readability for multi-layer bookshelves, and connecting couples of multi-layer bookshelves with multiplexers and $u$ updating the tag reading status in the computer terminal database.



Fig. 8. Flow chart of optimal library inventory technology.

\subsection{Deciding tag type and finding optimal antenna reader location}

In this study, the authors propose an optimal library inventory system based on electromagnetic identification 
(EMID) technology with the advantages of using electromagnetic (EM) tag and radio frequency identification (RFID) tag. Besides, embedded electromagnetic identification (EMID) security strips, as shown in Fig. 9, are used for securing and managing the stocks on the library bookshelves. With security advantage and radio frequency identification (RFID) tags with advantages of managing distribution and miniature, this kind of tag combines the technology of electromagnetic (EM) strips.

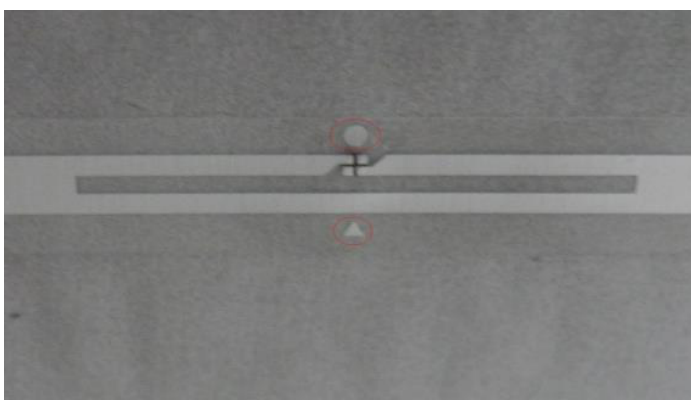

Fig. 9. EMID security strips.

Fig. 10 is the architecture of a bookshelf with the width and height of $90 \mathrm{~cm}$ and $19 \mathrm{~cm}$, respectively. In this study, three places labeled as A, B and C in Fig. 2, are tested to find the optimal antenna reader location. The place $\mathrm{A}$ is located on the left hand side of the bookshelf; the place $\mathrm{B}$ is located on the middle of the bookshelf; the place $\mathrm{C}$ is located either on the $30 \mathrm{~cm}$ from the distance of left or right hand sides of the bookshelf.

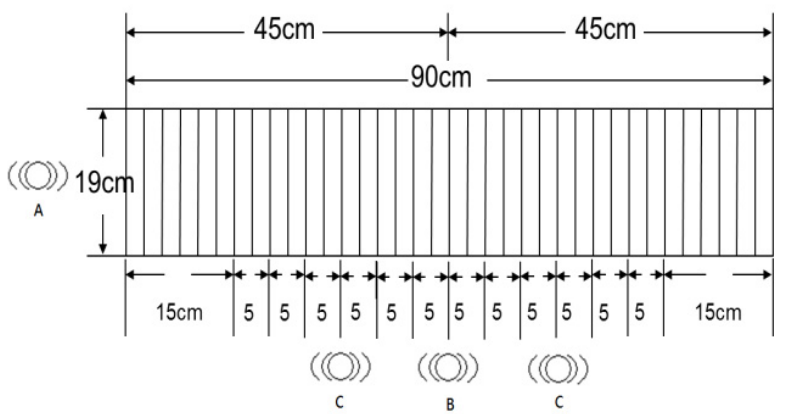

Fig. 10. Antenna locations on the one layer bookshelf.

\subsection{Connecting multi-layer bookshelves and testing tag readability}

Fig. 11 illustrates the structure of connecting multi-layer bookshelves in a library by using multiplexers. As shown in Fig. 11, by rolling every EMID tag, the library computer terminal through multiplexers and readers obtains antenna's signals. The database of the computer will authenticate the location of the book after the computer obtained the EMID tag signal. This indicates that whether the book is on the bookshelf or not the library inventory work can be automatically done. Fig. 12 shows antenna's locations in a multi-layer bookshelf to test the tag readability.

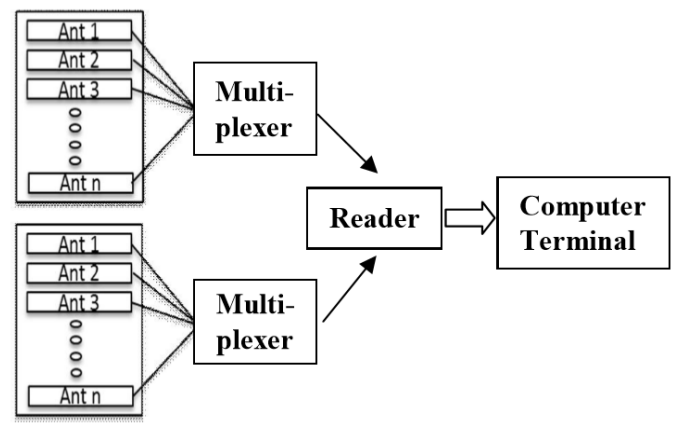

Fig. 11. Connection of multi-layer bookshelves.

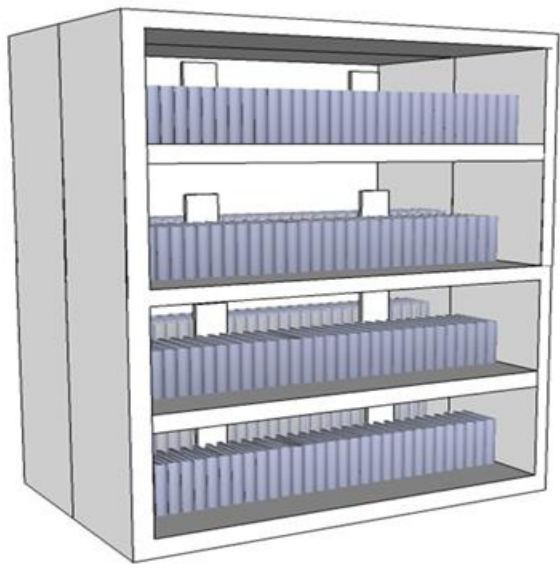

Fig. 12. Antenna locations in multi-layer bookshelves.

\subsection{Integrate tag-reading status and computer database terminal on software}

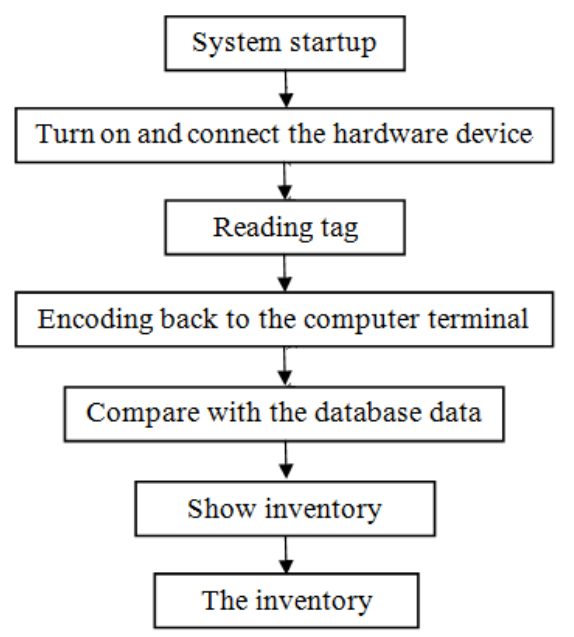

Fig.13. Flow chart of inventory system implementation.

Fig. 13 illustrates the flow chart of the inventory system technology implementation which includes seven steps: system startup, turning on and connecting the hardware device, reading tag code, encoding back to the computer terminal, comparing with the database data, showing inventory results, and the inventory ends. Fig. 14 shows the user interfaces of reading EMID tag strips 
and administrator's database management in Chinese on the part of the computer system in which the user interface and database are built by $\mathrm{C}++$ codes. There are six main functions shown on the screen of Fig. 14(a), including IP address setting of the main-control-unit Multiplex Master, the subordinate-unit-multiplexer (Slave) of the main-control-unit Multiplex Master, determining the antenna port the RFID Reader will transmit and receive, and displaying the antenna connection status (the antenna number hole will display a green light when the antenna is connected). As for Fig. 14(b), there are five main functions shown on the screen, including EMID tag number, book title, author's name, publisher, and reading status. According to the experimental results, the proposed system with easy operations, by checking the screen of Fig. 14(b), allows the library administrator to identify whether a book is on the bookshelf or not and to accomplish library inventory work efficiently and effectively. The relevant test results will be described in the next section.

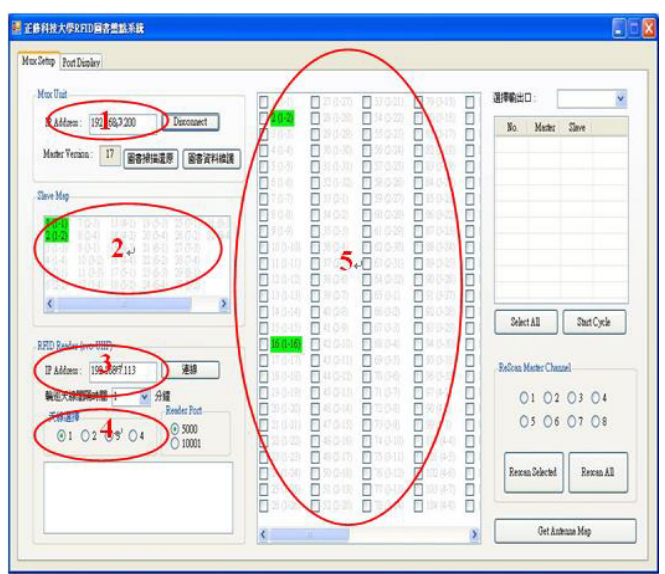

(a) reading EMID tag

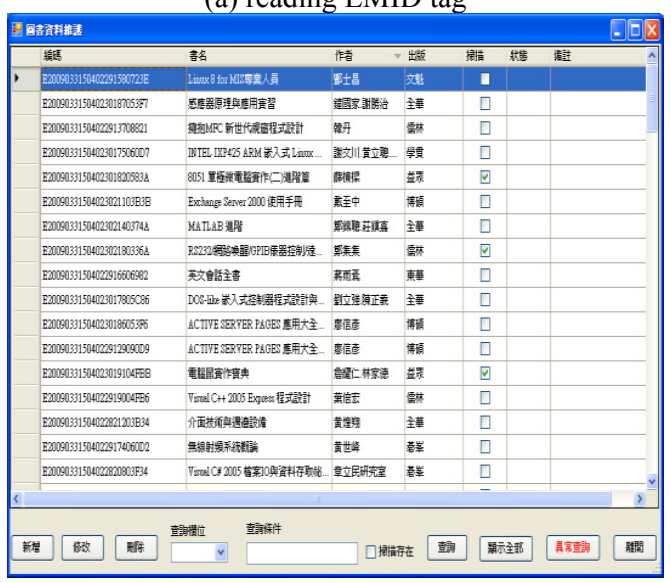

(b) book database management

Fig. 14. User interfaces for managing stocks in library (a) reading EMID tag (b) book database management.

\section{Experimental results and discussion}

In order to minimize the disturbance during testing, the proposed system is experimented at night during the library closing time interval. Based on the polling inquiry methodology, the system would automatically read every EMID tag individually by switching different multiplexers gradually. On the other side, the user interface of the computer terminal would show the reading status of each EMID tag and the reading data is then stored in the computer terminal database.

Table 2. Reading rate for different RFID tag locations.

\begin{tabular}{|c|c|c|c|}
\hline $\begin{array}{c}\text { EMID Tag } \\
\text { Quantity }\end{array}$ & Location & $\begin{array}{c}\text { Reading } \\
\text { Quantity }\end{array}$ & $\begin{array}{c}\text { Reading } \\
\text { Rate (\%) }\end{array}$ \\
\hline \multirow{3}{*}{30} & $\mathrm{~A}$ & 15 & $50 \%$ \\
\cline { 2 - 4 } & $\mathrm{B}$ & 30 & $100 \%$ \\
\cline { 2 - 4 } & $\mathrm{C}$ & 30 & $100 \%$ \\
\hline
\end{tabular}

Table 2 shows the reading rate of EMID tags located at $\mathrm{A}, \mathrm{B}$, and $\mathrm{C}$ places as shown in Fig. 3. From Table 1, the reading rate of 30 EMID tag strips at the location $\mathrm{A}$, $\mathrm{B}$, and $\mathrm{C}$ are $50 \%, 100 \%$, and $100 \%$, respectively. This implies that either location $\mathrm{B}$ or $\mathrm{C}$ gets better reading rate. Table 2 gives the reading rate of 25 EMID tag strips with different measuring time for one-sided bookshelf.

Table 3. Reading rate for one side bookshelf.

\begin{tabular}{|c|c|c|c|}
\hline $\begin{array}{c}\text { EMID Tag } \\
\text { Quantity }\end{array}$ & $\begin{array}{c}\text { Time } \\
\text { Interval(Min.) }\end{array}$ & $\begin{array}{c}\text { Reading } \\
\text { Quantity }\end{array}$ & $\begin{array}{c}\text { Reading } \\
\text { Rate (\%) }\end{array}$ \\
\hline \multirow{3}{*}{25} & 1 & 15 & $60 \%$ \\
\cline { 2 - 4 } & 3 & 23 & $88 \%$ \\
\cline { 2 - 4 } & 5 & 25 & $100 \%$ \\
\hline
\end{tabular}

From Table 3, the reading rate of 25 EMID tag strips with the time interval of 1,3 , and 5 minutes are $60 \%$, $88 \%$, and $100 \%$, respectively. This implies that measuring time with 5 minute interval gets the best reading rate.

Table 4. Reading rate for two side bookshelves.

\begin{tabular}{|c|c|c|c|}
\hline $\begin{array}{c}\text { EMID Tag } \\
\text { Quantity }\end{array}$ & $\begin{array}{c}\text { Time } \\
\text { Interval(Min.) }\end{array}$ & $\begin{array}{c}\text { Reading } \\
\text { Quantity }\end{array}$ & $\begin{array}{c}\text { Reading } \\
\text { Rate (\%) }\end{array}$ \\
\hline \multirow{3}{*}{30} & 1 & 17 & $56.6 \%$ \\
\cline { 2 - 4 } & 3 & 24 & $80 \%$ \\
\cline { 2 - 4 } & 5 & 28 & $93.3 \%$ \\
\hline
\end{tabular}

Table 4 illustrates the reading rate of 30 EMID tag strips with different measuring time for two-sided bookshelves. From Table 4, the reading rate of 30 EMID tag strips with the time interval of 1,3 , and 5 minutes are $56.6 \%, 80 \%$, and $93.3 \%$, respectively. This implies that measuring time with 5 minute interval gets the best reading rate.

As for experimental results, when the bookcase with width and depth being $90 \mathrm{~cm}$ and $19 \mathrm{~cm}$ is chosen, the receiving angle must exceed 136.4 degree. And when the choice of the bookshelf length is $90 \mathrm{~cm}$, the receiving angle can be reduced to 112.6 degree. In general, the width of the library shelves is mostly between 90-150 $\mathrm{cm}$, so the omni-directional radiation antenna has a good performance of wide beam and omni-directional radiation advantage, more suitable for library inventory management. 


\section{Conclusion}

This paper presents the RFID system used in the library inventory management, RFID antenna design and the actual test results. We propose a RFID antenna design method and focus on the diffusion range of omnidirectional field radiation. The center frequency of the designed RFID antenna works in the UHF $915 \mathrm{MHz}$, and is made on the printed circuit board as well as the plane structure, making it easy to be applied in the book inventory system. The features of the real-made antenna include a good gain and omni-directional radiation pattern, a simple architecture and low manufacturing cost. The results show that the omni-directional radiation antenna has good performance of omnidirectional radiation advantage and good detection accuracy, suitable for use in library shelves for large-scale book inventory operations and it can save a lot of manpower and reduce the risk of manual errors. In addition, an optimal library inventory system based on EMID technology has been proposed in this study. The main contribution of the proposed system is to improve traditional human labor-based library inventory methodology by decreasing the inventory processing time and reducing the possibility of the books being misplaced.

\section{References}

1. C.W. Chou, The application of radio frequency identification technology to the library real-time storage, Department of Engineering Science, National Cheng-Kung University, Kaohsiung, Taiwan, 2006

2. M.S. Selamat, B.Y. Majlis, Challenges in implementing RFID tag in a conventional library, IEEE Conf. on Semiconductor Electronics, 258262 (2006)

3. S.F. Chiou, S.K. Lin, S.L. Chen, Dual-radiation pattern RFID tag design for application in library management, IEEE 4th Asia-Pacific Conf. on Antennas and Propagation, 176-178 (2015)

4. R.J. Miao, J. Xu, J.S. Wu, Y.R. Zheng, H.H. Gao, Design and implement of libaray intelligent management system based on RFID, International 4th Conf. on Intelligent Systems Design and Engineering Applications, 288-291 (2015)

5. C. Feng, Research for application of RFID in library, IEEE Conf. on Computer and Communication Technologies in Agriculture Engineering, 262-264 (2010)

6. A. Boursianis,T. Samaras, A.C. Polycarpou and J.N Sahalos, A UHF RFID reader antenna for searching tagged items, IEEE Conf. on RFID Technology and Applications, 193-198 (2014)

7. I. Ehrenberg, C. Floerkemeier, S. Sarma, Inventory management with an RFID-equipped mobile robot. IEEE Conf. on Automation Science and Engineering, 1020-1026 (2007)

8. C. R. Medeiros, J. R. Costa, C. A. Fernandes, RFID smart bookshelf with confined detection range at
UHF. European Conf. on Antenna and Propagation, 2779- 2783 (2009)

9. U. Kim, J. Choi, Design of a wideband rectangular loop tag antenna for UHF RFID library management, Microwave and Optical Technology Letters, 1439-1445, (2010)

10. P.Y. Lau, K.K. Yung, E.K. Yung, A low-cost printed CP patch antenna for RFID smart bookshelf in library, IEEE Transactions on Industrial Electronics, 57,1583-1589 (2010)

11. U. Kim, J. Koo, J. Choi, Design of a UHF band RFID tag antenna for library management system application, Asia-Pacific Microwave Conference, 1-4 (2008)

12. I.J. Lukas, X. Qing, Z.N. Chen, A. Alphone, UHF omnidirectional bent dipole antenna for item-level RFID applications, IEEE International Symposium on Antennas and Propagation Society, 1-4 (2008)

13. K.T. Kaiwen, X. Qing, C.K. Goh, L. Zhu, IEEE International Symposium on Antennas and Propagation Society, 1-4 (2010)

14. P. Golding and V. Tennant, Performance characterization for two radio frequency identification inventory readers within a university library environment, International Journal of Radio Frequency Identification Technology and Applications, Special Issue on RFID-Enhanced Technology Intelligence and Management, $107-$ 123 (2011)

15. L. Wang, RFID-based technology intelligence in libraries, International Journal of Technology Intelligence and Planning, 32-41 (2010)

16. D. Zhang, X. Shi, Self-service management platform design for library based on RFID. 2nd International Conference on Artificial Intelligence, Management Science and Electronic Commerce, 7237-7240 (2011)

17. A.T. Bin Abdullah, I.B. Ismail, A.B. Ibrahim, M.Z. Hakim Bin Noor, Library shelf management system using RFID technology, IEEE International Conf. on System Engineering and Technology, 215$218(2011)$

18. D.Y. Li, S.D. Xie, R.J. Chen, H.Z. Tan, Design of Internet of Things System for Library Materials Management using UHF RFID, IEEE International Conf. on RFID Technology and Applications, 4448 (2016)

19. X.Z. Huang, Application practice and analysis research of RFID technology in digital library, International Symposium on Information Technologies in Medicine and Education, 473-475 (2012)

20. P. Golding, V. Tennant, Work in Progress: Performance and reliability of radio frequency identification (RFID) library system, International Conference on Multimedia and Ubiquitous Engineering, (1143-1146) 2007

21. I. Ehrenberg, C. Floerkemeier, and S. Sarma, Inventory management with an RFID-equipped mobile robot, IEEE Conf. on Automation Science and Engineering, 1020-1026 (2007) 
22. Z.A. Mohideen, S. Muhamad, M.P. Ghadzali and M.R.M. Arshad, A practical approach to radio frequency identification library management system, IEEE Conf. on RFID-Technologies and Applications, 323-329 (2012)

23. H.M. Cheng, L. Huang, H. Xu, Y.F. Hu, X.A. Wang, Design and implementation of library books search and management system using RFID technology, International Conference on Intelligent Networking and Collaborative, 329-327 (2016)

24. Osama M. Haraz,Abdel-RazikSebak, Quadband planar PCB antenna for WLAN and mobile WiMAX applications, IEEE International Symposium on Antennas and Propagation, 416-418 (2011) 